OPEN ACCESS

Edited by:

Sarantis Livadas,

Metropolitan Hospital, Greece

Reviewed by:

Anna Kågesten

Karolinska Institutet (KI), Sweden

Akon Emmanuel Ndiok,

University of Calabar, Nigeria

*Correspondence:

Kamil Fusein

kfuseini@popcouncil.org

Specialty section:

This article was submitted to

Reproductive Epidemiology,

a section of the journal

Frontiers in Reproductive Health

Received: 08 November 2021

Accepted: 12 January 2022

Published: 04 February 2022

Citation:

Fuseini K, Jarvis L, Hindin MJ, Issah K and Ankomah $A$ (2022) Impact of COVID-19 on the Use of Emergency

Contraceptives in Ghana: An Interrupted Time Series Analysis. Front. Reprod. Health 4:811429 doi: 10.3389/frph.2022.811429

\section{Impact of COVID-19 on the Use of Emergency Contraceptives in Ghana: An Interrupted Time Series Analysis}

\author{
Kamil Fuseini ${ }^{1 *}$, Leah Jarvis ${ }^{2}$, Michelle J. Hindin ${ }^{2}$, Kofi Issah $^{3}$ and Augustine Ankomah ${ }^{1}$ \\ ${ }^{1}$ Population Council, Accra, Ghana, ${ }^{2}$ Population Council, New York, NY, United States, ${ }^{3}$ Family Health Division, Ghana \\ Health Service, Accra, Ghana
}

The Coronavirus disease pandemic has disrupted reproductive health services including decline in the use of pre-coital contraceptives. However, evidence of its impact on the use of emergency contraceptives, often, post-coital methods, is limited in the emerging literature, hence this study. Data on total number of emergency contraceptive users from January 2018 to February 2020 (pre-pandemic) and March to December 2020 (during the pandemic) were extracted from the Ghana Health Service District Health Information Management System. Interrupted Time Series analysis was used to estimate the impact of the pandemic on the trend of emergency contraceptive use, adjusting for serial autocorrelation and seasonality. The results showed a gradual upward trend in emergency contraceptive use before the pandemic, increasing at a rate of about 67 (95\% Cl 37.6-96.8; $p=0.001$ ) users per month. However, the pandemic caused a sudden spike in the use of emergency contraceptives. The pandemic and its related restrictions had an immediate effect on the use of emergency contraceptives, increasing significantly by about 1939 users (95\% Cl 1096.6-2781.2; $p=0.001)$ in March 2020. Following March 2020, the number of emergency contraceptive users continued to increase by about 385 users per month (95\% $\mathrm{Cl} 272.9-496.4 ; p=0.001)$. The evidence shows that use of emergency contraceptives, often used as post-coital methods for unprotected sex was not negatively impacted by the pandemic. In fact, it is the opposite. Hence, in planning for similar situations attention should be given to the distribution of post-coital contraceptive methods.

Keywords: COVID-19, family planning, emergency contraception, oral, Ghana

\section{INTRODUCTION}

Infectious disease outbreaks often disrupt economic, social, educational, and health systems (1-3).

In March 2020, the World Health Organization declared the coronavirus disease of 2019 (COVID-19) a global pandemic. Worldwide, the burden of the pandemic on health systems has impacted Sexual and Reproductive Health (SRH) services and programs among others (4).

SRH services have been affected by governments' response to the pandemic, such as lockdowns, stay at home and/or work from home directives, physical distancing, and travel restrictions (4-6). Even where there are only limited COVID-19 related restrictions, the fear of contracting the virus may limit client's use of health facilities for non-essential services such as contraceptives $(7,8)$. 
Studies have shown that infectious disease outbreaks have negative implications for the uptake of contraceptive services. For instance, at the peak of the Ebola epidemic, distribution of contraceptives declined significantly in Liberia by $65 \%$ and in Sierra Leone by $23 \%$ (1).Specific contraceptive methods such as implants, male condom, pills, and injectables showed similar declines (1). A study in rural Guinea also showed that utilization of contraceptive services decreased by half, from a monthly average of 531 visits before the Ebola epidemic to 242 visits in the peak month of the Ebola outbreak (9). Similar dips in FP visits were observed across the different FP methods (9).

Specific to the COVID-19 pandemic, studies have shown its negative impact on the uptake of various contraceptives $(10,11)$. It has been estimated that the potential impact of COVID-19 on contraceptive use could result in a fall of about 60 million fewer users of modern contraception worldwide in 2020 (11). In Mozambique, the imposition of the state of emergency due to COVID-19 led to a modest short-term drop in both FP service provision and utilization, although it was followed by a relatively rapid rebound (12). In Bangladesh, COVID-19 had a sustained disruption of FP service provision in the short- and mid-term analyses of trends before, during, and after COVID-19 lockdowns (13). Specifically, long-acting reversible contraceptives (LARCs) were more severely affected, with severe immediate impacts on implant and IUD service provision with shorter-acting methods declining at a smaller magnitude (13).

Indeed, the impact of the pandemic on contraceptive use depends on several factors such as the methods used by couples, types of disruptions experienced, and their need for contraceptives at a particular point in time (11). However, the literature has almost exclusively focused on the impact of COVID-19 on the use of pre-coital contraceptive methods, with limited attention given to the impact of COVID-19 on the use of post-coital contraceptives (2,10-13). Hence, there is limited empirical evidence on the impact of infectious disease outbreaks on the use of emergency contraceptives (ECs) in a pandemic situation.

Ghana confirmed its first two cases of COVID-19 on March 12, 2020. As a result, the government, and stakeholders started the implementation of the Ghana Emergency Preparedness and Response Plan (2020). Under the Emergency Powers Act and the Public Health Act (Act 851), the government restricted mass religious, social, and sporting gatherings suspended international travel, closed educational institutions at all levels, and imposed a partial lockdown on the metropolitan localities of Accra, Kumasi, Tema, and the environs of Kasoa. The partial lockdown lasted for 3 weeks and was lifted on $19^{\text {th }}$ April 2020. However, the other restrictive and preventive protocols continued (14).

ECs are very important in the contraceptive method mix. It is often used by women who have had unprotected sex or as a backup in cases of perceived failure of traditional methods like withdrawal or condom breakage (15-19). In some African countries, ECs are provided in both public and private health facilities; however, they are mostly accessed through private pharmacies and chemical drug stores (20), usually due to convenience, quickness, and confidentiality (21).
In Ghana, national-level surveys have shown that knowledge of ECs among all women increased from 28.2\% in 2003 (22) to $68.7 \%$ in 2017 (23). In 2017, the current use of ECs was $1.3 \%$ among all women, $0.9 \%$ among currently married women, and $5.4 \%$ among sexually active unmarried women (24). Smallscale studies in Ghana have also shown similar results. In a study to assess the awareness, use, and associated factors of ECs among women of reproductive age in northern Ghana, 63\% of students in a university had heard of ECs and $37 \%$ had used it (25). Another study found that among female senior high school students in Ho municipality in the Volta Region of Ghana, knowledge of ECs was $98.8 \%$, while $57.1 \%$ of students had a history of EC use (26). Furthermore, a study among young people aged 15-24 years in Accra, found that ECs were the second most popular modern contraceptive method among women, next to condoms (27). Another study in Accra revealed that of all sexually experienced women in the study, $14.5 \%$ reported having ever used EC at any point in time (16).

ECs are preferred as convenient post-coital methods $(18,28)$, and while evidence from elsewhere shows that infectious disease outbreaks including COVID-19 impact negatively on the use of specific contraceptive methods, there is limited empirical evidence on the impact of COVID-19 on the use of ECs specifically. This study sought to assess the impact of the Covid19 pandemic on the use of ECs, in a country where knowledge of EC is high $(24,27,29)$ by comparing pre pandemic data with data during the early phase of the pandemic. Given that in Ghana, sexual intercourse is often unplanned (18), and COVID-19 risk mitigation strategies led to people staying at home, this may lead to an increase in EC use, as it is widely available inside and outside of health facilities within communities.

\section{MATERIALS AND METHODS Study Design}

The study used the Interrupted Time Series (ITS) design. This design can be used to make comparisons across time within a population. Generally, it is applied to natural experiments with an intervention introduced at a known point in time (30). The ITS study design uses data collected at regular intervals over time, and can be used for a pre-post comparison while accounting for underlying trends in the outcome variable $(30,31)$.

\section{Data}

This study utilized data on EC users extracted from the Ghana District Health Information Management System (DHIMS2) database in February 2021. DHIMS2 is a web-based application for remotely compiling data across different levels of the health system (i.e., public, and private including pharmacies and chemical stores) to a central storage point. The system is used to capture data on various health service indicators including the different types of contraceptive methods (e.g., implants, condoms, IUD, injectables, and ECs) (32). The extracted data were on EC users from January 2018 to December 2020. See details of the distribution of EC users over the study period in Table 1. The data were exported to STATA version 16 for analysis. 
TABLE 1 | Distribution of EC users by month in Ghana, 2018-2020.

\begin{tabular}{|c|c|c|c|c|c|c|}
\hline Month & \multicolumn{2}{|c|}{2018} & \multicolumn{2}{|c|}{2019} & \multicolumn{2}{|c|}{2020} \\
\hline February & 4.0 & 618 & 4.7 & 1,124 & 4.5 & 3,104 \\
\hline March & 9.1 & 1,421 & 7.9 & 1,920 & 6.1 & 4,199 \\
\hline April & 10.9 & 1,693 & 9.0 & 2,178 & 7.4 & 5,099 \\
\hline June & 15.0 & 2,337 & 9.1 & 2,209 & 8.4 & 5,773 \\
\hline July & 13.2 & 2,047 & 10.8 & 2,600 & 10.2 & 6,957 \\
\hline August & 9.7 & 1,505 & 8.4 & 2,018 & 12.5 & 8,578 \\
\hline September & 5.5 & 854 & 7.9 & 1,912 & 8.3 & 5,684 \\
\hline October & 5.8 & 897 & 11.1 & 2,676 & 10.2 & 6,977 \\
\hline
\end{tabular}

Source of data, DHIMS2, Ghana.

\section{Variables}

The outcome variable of interest was use of EC, defined as the total number of FP clients who used ECs per month over the period under study. Use of EC was measured as a continuous variable. Months were included in the analysis to control for seasonality measured as dummy variables $(1=$ Yes, $0=$ otherwise), using January as the reference category.

\section{Statistical Analysis}

To assess the impact of the pandemic on the use of ECs, trends in the monthly number of EC users were assessed before and during the COVID-19 pandemic. The study period was divided into two phases: 26 months of pre-COVID-19 data (January 2018 to Feb 2020) and 10 months of data during COVID-19 (March 2020 to December 2020), which is enough to have sufficient power (34). With the onset month of COVID-19 and its preventive measures (March 2020) as the start of the event, ITS segmented ordinary least square regression model was estimated to assess the impact of COVID-19 on the use of ECs. The analysis was conducted using the Prais-Winsten method to account for the effect of serial autocorrelation (33) and took into consideration the potential seasonal effect of ECs uptake by including months as dummy indicator variable in the model. The interrupted time series regression model (single group) takes the form of:

$$
Y_{t}=\beta_{0}+\beta_{1} T_{t}+\beta_{2} X_{t}+\beta_{3} X_{t} T_{t}+\epsilon_{t}
$$

Where $Y_{t}$ is the aggregated outcome variable measured at each equally spaced time point $t$. $\beta_{0}$ represents the intercept or starting level of the outcome variable (estimated number of EC users at the beginning of the pre-outbreak period). $\beta_{1}$ estimates the monthly change in the number of EC users until the onset of the COVID-19 pandemic. $T_{t}$ is the time since the start of the study. $\beta_{2}$ represents the change in the level of EC use that occurred in the period immediately following the onset of COVID-19 (compared with the counterfactual). $\beta_{3}$ represents the difference between the trend in EC use pre-COVID-19 and during COVID19 periods. $X_{t}$ is a dummy (indicator) variable representing the onset of COVID-19 (pre-COVID-19 period 0, otherwise 1). $X_{t} T_{t}$ is an interaction term and $\epsilon_{t}$ is the random error term. The ITSA analysis was implemented using the "itsa" command in STATA (33).

\section{RESULTS}

Table 1 shows the distribution of EC users by month from January 2018 to December 2020. In general, EC use increased across the 3 years. Use of ECs from January 2018 to December 2020 was 108246 (15560 in 2018, 24167 in 2019, and 68519 in 2020). The number of EC use increased from 1296.7 in 2018 to 2013.9 in 2019 and further increased to 5709.9 in 2020. In 2018, the highest proportion of EC use was in June (15\%), followed by July (13.2\%), and April (10.9\%) and May (10.9\%). The lowest proportion of EC use was in February (4.0\%). In 2019, use of EC was highest in October (11.1\%) and lowest in January (4.4\%). In 2020, use of EC was highest in August (12.5\%) and lowest in January (2.4\%).

Table 2 visualized in Figure 1 shows EC use over the 26 months (January 2018 to Feb 2020) before the first COVID-19 confirmed case in Ghana and 10 months of data since the first confirmed case of COVID-19 (March 2020 to December 2020). It was estimated that in January 2018 (at baseline), there were 333.2 EC users [95\% CI $(-240.2,906.5)] . I$ In each month, from February 2018 to March 2020, the number of EC users rose significantly by 67 users per month $[p \leq 0.001,95 \%$ CI (37.6-96.8)].

When the COVID-related restrictions began in March 2020, there was a significant increase in the number of EC users by $1938.9[p \leq 0.001,95 \%$ CI $(1096.6,2781.2)]$ compared to the pre COVID-19 level. Comparing the pre-COVID-19 trend to 
TABLE 2 | Parameter estimates of the impact of COVID-19 pandemic on EC users in Ghana, 2018-2020.

\begin{tabular}{|c|c|c|c|c|}
\hline & Coef. & S. E. & $95 \%$ C. I. & \\
\hline Number of EC users in Jan. 2018 & 333.2 & 275.7 & -240.2 & 906.5 \\
\hline $\begin{array}{l}\text { Monthly change in number of EC } \\
\text { users, Jan. 2018-Feb. } 2020\end{array}$ & $67.2^{\star \star \star}$ & 14.2 & 37.6 & 96.8 \\
\hline $\begin{array}{l}\text { Change in the level of EC users in } \\
\text { Mar. } 2020\end{array}$ & $1938.9^{\star \star \star}$ & 405.0 & 1096.6 & 2781.2 \\
\hline $\begin{array}{l}\text { Change in trend in monthly number of } \\
\text { EC users between Jan 2019-Feb. } \\
2020 \text { compared to Mar.-Dec. } 2020\end{array}$ & $317.4^{\star \star \star}$ & 53.4 & 206.3 & 428.6 \\
\hline $\begin{array}{l}\text { Monthly change in number of EC } \\
\text { users from Mar.-Dec. } 2020\end{array}$ & $384.6^{\star \star \star}$ & 53.7 & 272.9 & 496.4 \\
\hline \multicolumn{5}{|l|}{ Month } \\
\hline \multicolumn{5}{|l|}{ January (Reference category) } \\
\hline February & 408.4 & 418.9 & -462.7 & 1279.5 \\
\hline June & $1000.5^{\star}$ & 429.5 & 107.3 & 1893.6 \\
\hline July & $1255.8^{\star \star \star}$ & 245.3 & 745.7 & 1765.9 \\
\hline August & 1248.5 & 744.7 & -300.3 & 2797.2 \\
\hline September & -141.5 & 314.8 & -796.2 & 513.1 \\
\hline October & 385.4 & 402.9 & -452.4 & 1223.3 \\
\hline November & 94.7 & 282.8 & -493.5 & 682.9 \\
\hline December & 99.2 & 455.5 & -848.1 & 1046.6 \\
\hline rho & -0.07146 & & & \\
\hline Durbin-Watson statistic (original) & 2.10913 & & & \\
\hline Durbin-Watson statistic (transformed) & 1.97073 & & & \\
\hline
\end{tabular}

${ }^{*} p<0.05 ; " * x<0.01 ; " * * * 0.001$. Source of data, DHIMS2, Ghana.

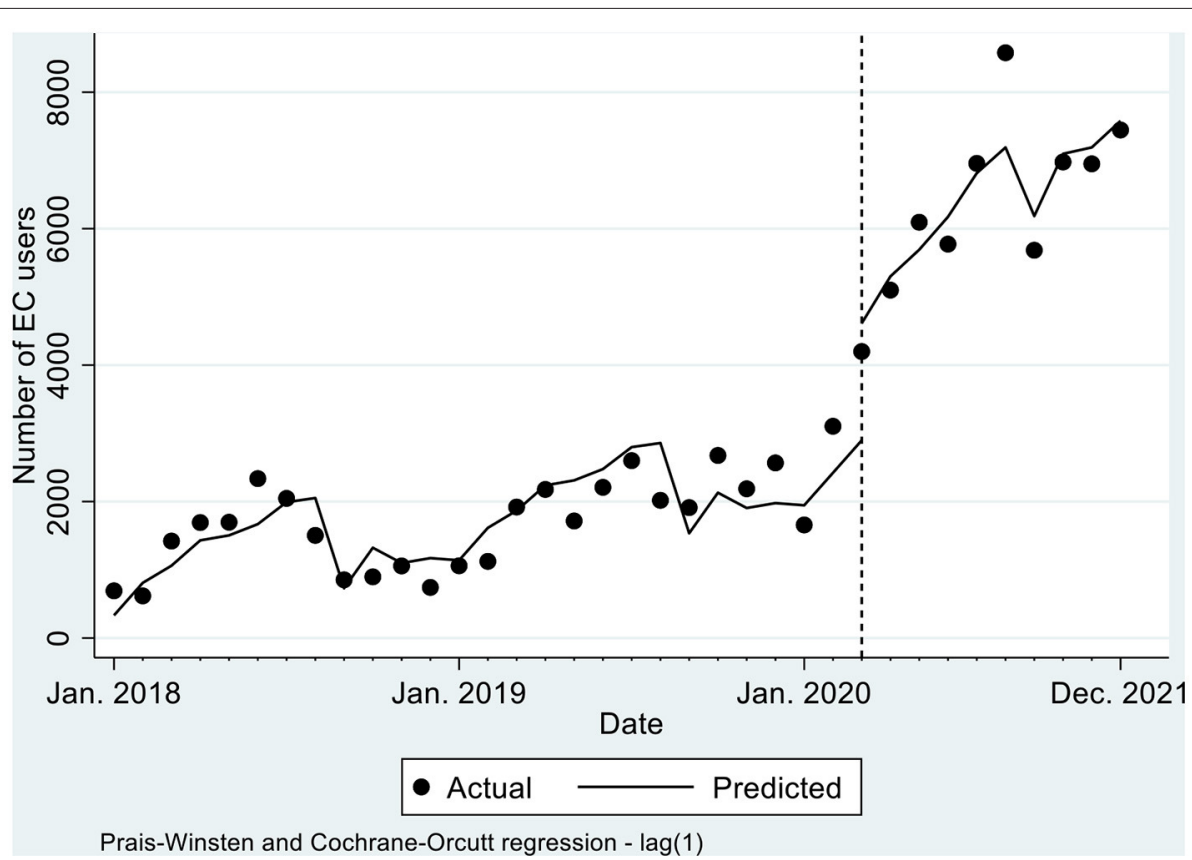

FIGURE 1 | Actual and predicted trends in total number of EC users, by month, 2018-2020. 
post-COVID-19; there was a statistically significant increase in the monthly trend of EC users by 317.4 per month $[p \leq 0.001$, 95\% CI $(206.3,428.6)]$. Similarly, after March 2020, there was a significant monthly increase in EC users at a rate of 384.6 per month $[p \leq 0.001,95 \%$ CI $(272.9,496.4)]$. Efforts were made to conduct further sub-national analysis by Ghana's 16 regions, however, there were not enough data in some regions to conduct robust analyses.

\section{DISCUSSION}

To the best of our knowledge, this is the first study to use routine service data to examine the impact of infectious disease outbreaks on ECs. This study used routine service data from DHIMS to assess the impact of the COVID-19 pandemic on the use of ECs in Ghana. The study considered January 2018 to February 2020 as the pre-COVID-19 period, and March to December 2020 as the COVID-19 period, and March 2020 as the onset month of the start of the event. Studies assessing the impact of infectious disease outbreaks on contraception have often considered pre-coital contraceptives. These studies have found that infectious disease outbreaks (including COVID-19) impact negatively on the use of contraceptives (i.e., oral contraceptives, injectables, IUD, and implants) (1,9). However, the results of this study revealed that the COVID-19 pandemic and its associated preventive measures rather led to an increase in the use of ECs in Ghana.

Although the trend in EC use before the COVID-19 pandemic was increasing significantly by about 67 users per month, in March 2020 (the interruption month), the number of EC users increased significantly to levels never observed before the pandemic (increased by 1,939 additional users). During the COVID-19 period, the number of EC users was increasing by about 385 users per month, resulting in a difference in trend between pre-and post-COVID-19 of about 317 EC users monthly. This is an indication that COVID-19 may have led to a sustained increase in the use of ECs in Ghana.

Various factors may explain these findings. The COVID-19 risk mitigation strategies starting from March 2020, emphasized on staying at home; hence, partners would be exposed to an increase in sexual activity. Evidence show that crisis or instability usually leads to an increase in unplanned pregnancies. For example, in 2006, the Yogyakarta earthquake in Indonesia resulted in the decrease in use of contraceptives leading to an increase in unplanned pregnancies (35). Hence, the inability of Ghanaian couples to plan for sexual encounters may have led to unprotected sexual encounters (18). To prevent unintended pregnancies, ECs may have become a convenient option as postcoital contraception with minimal side effects $(15,18,21)$. The restriction in movements making partners stay at home may have increased unplanned and unprotected sexual intercourse resulting in the increase in use of ECs. Put together, these factors may explain the sustained increase in ECs use between March and December 2020. It is important to note that public and private health facilities provided health services including contraceptives during the COVID-19 pandemic period. ECs were readily available since restrictions in movement did not include visits to government and private pharmacies to procure products.

The findings of this study show that the impact of infectious disease outbreaks on use of EC may differ from what other studies have found about other methods of contraception, specifically pre-coital methods. While studies show that pandemics have a negative impact on use of contraceptives such as implants and IUDs, this study shows that the COVID-19 pandemic may have led to an increase in use of ECs. The data used for this analysis is routine service data; hence, there may have been disruptions in data capturing during the COVID-19 period, thus the increase in EC use could have been underestimated.

\section{LIMITATIONS}

Repeat use of ECs could have led to double counting, however, evidence in Ghana shows that multiple use of ECs within a month is minimal (16). There was also limited data in DHIMS on sociodemographic characteristics, where available, it did not lend itself to these kinds of analyses. This limitation notwithstanding, the statistical analyses are appropriate and robust and allow for interpretation of results to inform decision-making.

\section{CONCLUSION}

The findings of this study demonstrate that the COVID-19 pandemic has had an impact resulting in the increase in use of ECs in Ghana. Studies show that use of pre-coital contraceptives has been found to decline during epidemics and pandemics. However, the findings of this study demonstrated the opposite for EC use, hence, policymakers, and service providers should prioritize the provision of ECs in similar situations. With evidence form other studies showing that access and utilization of other forms of contraceptives being impacted negatively, and scarce resources being channeled to COVID-19 response, the contribution of ECs to the overall contraceptive uptake in Ghana should not be neglected.

\section{DATA AVAILABILITY STATEMENT}

Publicly available datasets were analyzed in this study. This data can be found here: The data used for this study are available from Ghana Health Service, upon reasonable request.

\section{ETHICS STATEMENT}

The project received ethics approval from the Ghana Health Ethics Review Committee (GHS-ERC 007/03/20).

\section{AUTHOR CONTRIBUTIONS}

$\mathrm{KF}, \mathrm{LJ}, \mathrm{MH}, \mathrm{KI}$, and AA were involved in the conceptualization of the manuscript and methods, involved in the write-up, and review of the final manuscript. KF conducted the data 
analysis. All authors contributed to the article and approved the submitted version.

\section{FUNDING}

This work was supported by the Bill and Melinda Gates Foundation (ID: INV-000782).

\section{REFERENCES}

1. Bietsch K, Williamson J, Reeves M. Family planning during and after the West African ebola crisis. Stud Fam Plann. (2020) 51:71-86. doi: 10.1111/sifp.12110

2. Ferreira-Filho ES, de Melo NR, Sorpreso ICE, Bahamondes L, Simões RDS, Soares-Júnior JM, et al. Contraception and reproductive planning during the COVID-19 pandemic. Expert Rev Clin Pharmacol. (2020) 13:61522. doi: $10.1080 / 17512433.2020 .1782738$

3. Nanda K, Lebetkin E, Steiner MJ, Yacobson I, Dorflinger LJ. Contraception in the era of COVID-19. Glob Health Sci Pract. (2020) 8:166-8. doi: 10.9745/GHSP-D-20-00119

4. Riley T, Sully E, Ahmed Z, Biddlecom A. Estimates of the potential impact of the COVID-19 pandemic on sexual and reproductive health in low- and middle-income countries. Int Perspect Sex Reprod Health. (2020) 46:736. doi: $10.1363 / 46 \mathrm{e} 9020$

5. UNFPA. COVID-19: A Gender Lens - Protecting Sexual and Reproductive Health and Rights, and Promoting Gender Equality. New York, NY: UNFPA (2020). p. 1-8. Available online at: https://www.unfpa.org/resources/covid19-gender-lens (accessed March 12, 2021).

6. WHO. COVID-19: Operational Guidance For Maintaining Essential Health Services During An Outbreak - Interim Guidance. Switzerland, Geneva: WHO (2020). p. 1-10. Available online at: https://apps.who.int/iris/bitstream/ handle/10665/331561/WHO-2019-nCoV-essential_health_services-2020.1eng.pdf (accessed March 12, 2021).

7. Afulani PA, Gyamerah AO, Nutor JJ, Laar A, Aborigo RA, Malechi H, et al. Inadequate preparedness for response to COVID-19 is associated with stress and burnout among healthcare workers in Ghana. PLoS ONE. (2021) 16:e0250294. doi: 10.1371/journal.pone.0250294

8. Yadav UN, Yadav OP, Singh DR, Ghimire S, Rayamajhee B, Mistry SK, et al. Perceived fear of COVID-19 and its associated factors among Nepalese older adults in eastern Nepal: a cross-sectional study. PLoS ONE. (2021) 16:e0254825. doi: 10.1371/journal.pone.0254825

9. Camara BS, Delamou A, Diro E, Béavogui AH, El Ayadi AM, Sidibé S, et al. Effect of the 2014/2015 Ebola outbreak on reproductive health services in a rural district of Guinea: an ecological study. Trans R Soc Trop Med Hyg. (2017) 111:22-9. doi: 10.1093/trstmh/trx009

10. Bolarinwa OA, Ahinkorah BO, Seidu A-A, Ameyaw EK, Saeed BQ, Hagan JE, et al. Mapping evidence of impacts of COVID-19 outbreak on sexual and reproductive health: a scoping review. Healthcare. (2021) 9:436. doi: 10.3390/healthcare9040436

11. Dasgupta A, Kantorová V, Ueffing P. The impact of the COVID-19 crisis on meeting needs for family planning: a global scenario by contraceptive methods used. Gates Open Res. (2020) 4:102. doi: 10.12688/gatesopenres.13148.2

12. Leight J, Hensly C, Chissano M, Ali L. Short-term effects of the COVID-19 state of emergency on contraceptive access and utilization in Mozambique. PLoS ONE. (2021) 16:e0249195. doi: 10.1371/journal.pone.0249195

13. Hossain MdI, Hossain MdS, Ainul S, Bhuiyan MdK, Hossain SMI, Rob U, et al. Trends in Family Planning Services in Bangladesh Before, During And After COVID-19 Lockdowns: Evidence From National Routine Service Data. Dhaka: Population Council (2020). doi: 10.31899/rh14.1038

14. Ministry of Health. Ghana COVID-19 Emergency Preparedness and Response Project \& Additional Financing: Environmental and Social Management Framework (ESMF). Accra, Ghana: Ministry of Health, Ghana (2020).

15. Chin-Quee D, Hinson L, L'Engle KL, Otterness C, Janowitz B. Bridge over troubled waters: considerations in transitioning emergency contraceptive users to hormonal methods. Contraception. (2012) 85:363-8. doi: 10.1016/j.contraception.2011.07.014

\section{ACKNOWLEDGMENTS}

The authors would like to express their gratitude to Bright Addo, Akua Danquah Obeng-Dwamena, Leonie A. Allorsey and Rachel $\mathrm{N}$. Anum for their support in this study. We also acknowledge Henry Safori from the Family Health Division of Ghana Health Service for helping us with extracting the data from DHIMS2.

16. Henry EG, Agula C, Agyei-Asabere C, Asuming PO, Bawah AA, Canning D, et al. Dynamics of emergency contraceptive use in Accra, Ghana. Stud Fam Plann. (2021) 52:105-23. doi: 10.1111/sifp.12154

17. L'Engle KL, Hinson L, Chin-Quee D. "I love my ECPs": challenges to bridging emergency contraceptive users to more effective contraceptive methods in Ghana. J Fam Plann Reprod Health Care. (2011) 37:14651. doi: 10.1136/jfprhc-2011-0077

18. Rokicki S, Merten S. The context of emergency contraception use among young unmarried women in Accra, Ghana: a qualitative study. Reprod Health. (2018) 15:1-10. doi: 10.1186/s12978-018-0656-7

19. Yam EA, Mnisi Z, Maziya S, Kennedy C, Baral S. Use of emergency contraceptive pills among female sex workers in Swaziland. J Fam Plann Reprod Health Care. (2014) 40:102-7. doi: 10.1136/jfprhc-2012-100527

20. Morgan Gwendolyn, Jill K, Ilene S. Characteristics and patterns of use of emergency contraception among urban women in Nigeria and Kenya. Stud Fam Plann. (2015) 45:59-72. doi: 10.1111/j.1728-4465.2014.00376.x

21. Both R. Emergency contraceptive use in Addis Ababa, Ethiopia: Challenging common assumptions about young people's contraceptive practices. Reprod Health Matters. (2015) 23:58-67. doi: 10.1016/j.rhm.2015.06.005

22. Ghana Statistical Service, Noguchi Memorial Institute for Medical Research, ORC Macro. Ghana Demographic and Health Survey 2003. Calverton: GSS, NMIMR, and ORC (2004).

23. Ghana Statistical Service (GSS), Ghana Health Service (GHS), ICF. Ghana Maternal Health Survey 2017. Accra: GSS, GHS, and ICF (2018).

24. Ghana Statistical Service, Ghana Health Service, ICF. Ghana Maternal Health Survey 2017. Accra: GSS, GHS, and ICF (2018).

25. Darteh EKM, Doku DT. Knowledge and usage of emergency contraceptives among university students in ghana. J Community Health. (2016) 41:1521. doi: 10.1007/s10900-015-0057-6

26. Konlan KD, Amoah RM, Saah JA, Doat AR, Konlan KD, Japiong M, et al. The use of emergency contraception among female senior high students in the Ho municipality of the Volta Region, Ghana. Int J Reprod Contracept Obstet Gynecol. (2020) 9:2383. doi: 10.18203/2320-1770.ijrcog20202316

27. Grindlay K, Dako-Gyeke P, Ngo TD, Eva G, Gobah L, Reiger ST, et al. Contraceptive use and unintended pregnancy among young women and men in Accra, Ghana. PLoS ONE. (2019) 13:1-13. doi: 10.1371/journal.pone.0201663

28. Hobbs M, Taft AJ, Amir LH. The emergency contraceptive pill rescheduled: a focus group study of women's knowledge, attitudes and experiences. J Fam Plann Reprod Health Care. (2009) 35:87-91. doi: 10.1783/147118909787931672

29. Ghana Statistical Service, Ghana Health Service, ICF International. Ghana Demographic and Health Survey 2014: Key Indicators. Rockville: GSS, GHS, and ICF International (2015).

30. Bernal LJ, Cummins S, Gasparrini A. Interrupted time series regression for the evaluation of public health interventions: a tutorial. Int J Epidemiol. (2017) 46:348-55. doi: 10.1093/ije/dyw098

31. Bernal LJ, Cummins S, Gasparrini A. The use of controls in interrupted time series studies of public health interventions. Int J Epidemiol. (2018) 47:2082-93. doi: 10.1093/ije/dyy135

32. Odei-Lartey EO, Prah RKD, Anane EA, Danwonno H, Gyaase S, Oppong FB, et al. Utilization of the national cluster of district health information system for health service decision-making at the district, sub-district and community levels in selected districts of the Brong Ahafo region in Ghana. BMC Health Serv Res. (2020) 20:1-15. doi: 10.1186/s12913-020-05349-5

33. Linden A. Conducting interrupted time-series analysis for single- and multiple-group comparisons. Stata 
$J$.

(2015) 15:480-500. doi:

$10.1177 / 1536867 X 15015$

00208

34. Penfold RB, Zhang F. Use of interrupted time series analysis in evaluating health care quality improvements. Acad Pediatr. (2013) 13:S38-44. doi: 10.1016/j.acap.2013.08.002

35. Hapsari ED, Widyawati, Nisman WA, Lusmilasari L, Siswishanto R, Matsuo $\mathrm{H}$. Change in contraceptive methods following the Yogyakarta earthquake and its association with the prevalence of unplanned pregnancy. Contraception. (2009) 79:316-22. doi: 10.1016/j.contraception.2008.10.015

Conflict of Interest: The authors declare that the research was conducted in the absence of any commercial or financial relationships that could be construed as a potential conflict of interest.
Publisher's Note: All claims expressed in this article are solely those of the authors and do not necessarily represent those of their affiliated organizations, or those of the publisher, the editors and the reviewers. Any product that may be evaluated in this article, or claim that may be made by its manufacturer, is not guaranteed or endorsed by the publisher.

Copyright $\odot 2022$ Fuseini, Jarvis, Hindin, Issah and Ankomah. This is an open-access article distributed under the terms of the Creative Commons Attribution License (CC $B Y)$. The use, distribution or reproduction in other forums is permitted, provided the original author(s) and the copyright owner(s) are credited and that the original publication in this journal is cited, in accordance with accepted academic practice. No use, distribution or reproduction is permitted which does not comply with these terms. 